\title{
The Effects of Water Absorption on an Ester Vinyl Resin System
}

\author{
Ledjane Lima Sobrinho*, Marysilvia Ferreira, Fernando Luiz Bastian \\ Department of Metallurgical and Materials Engineering, \\ F 212, COPPE/UFRJ, 21941-972 Rio de Janeiro - RJ, Brazil
}

Received: April 28, 2009; Revised: August 18, 2009

\begin{abstract}
Derakene is a vinyl ester resin largely employed as matrix for polymeric based composite systems. In this work, the performance of such polymeric system was evaluated considering the effect of hygrothermal aging. The mechanical and thermal properties were examined for the processed material before and after ageing in water at $60{ }^{\circ} \mathrm{C}$ for a maximum period of 64 days. Both analyses indicated the occurrence of post cure of the system after 16 days due to exposition at $60{ }^{\circ} \mathrm{C}$ in water, which was also confirmed by analyses in samples with post cure treatment. Moreover, it was observed plasticizing of resin after 36 and 64 days of ageing. Micro structural and fracture surface analyses were carried out in order to characterize the samples. The appearance of surface voids was also observed.
\end{abstract}

Keywords: polymer, vinyl ester resin, mechanical properties, hygrothermal ageing

\section{Introduction}

Polymer based composites have been increasingly used in recent years as an advantageous option to conventional materials mainly metallic ones. Some of the benefits are the excellent corrosion and fatigue resistance associated with a high specific strength. Such characteristics fulfill the more and more severe materials requirements in several industrial sectors such as building and construction, oil and gas, naval, aerospatiale, among others that are gradually introducing composite materials into their main products and processes.

The environment to which the composites are exposed, however, can drastically limit their performance. For instance, the presence of humidity is pointed out as one of the main causes of polymeric composites failure since organic matrices can be largely affected by the presence of water ${ }^{1,2}$. In tropical environments, relative humidity close to $90 \%$ can be found and can drastically compromise composite performance. Therefore, the knowledge of the organic matrix limitations and ageing mechanisms in the presence of water is critical in order to guarantee successful composite application, since water diffusion is well known to be a limiting factor in the use of fiber reinforced polymer composites ${ }^{2}$.

When selecting a polymeric resin for use in a structural composite several factors must be considered, namely, strength, stiffness, toughness and durability. In the stage of selection, information regarding environment, service temperature, manufacture method, cure conditions and properties required are also important.

The most commonly employed thermoset resin for matrixes in structural composites is epoxy, which is normally the best technical choice even though at higher costs ${ }^{3}$. Polyester resins, on the other hand, although low cost materials, have several drawbacks for environment aggressive applications. They are known for their weak chemical resistance, mainly to hydrolysis, while epoxy resins present processing difficulties due to their high viscosity, long cure cycles and toxicity of some curing agents (hardeners) ${ }^{3}$. Vinyl ester resins are the addition product of an epoxy resin and an unsaturated carboxyl acid with a molecular structure quite similar to that of the polyester resin. The main difference lays on the location of its reactive groups which are only in the end chain (Figure 1). These materials were developed in an attempt to combine the mechanical and thermal properties of epoxy resins with the rapid cure of unsaturated polyesters. Additionally, its cost is also an advantage since is 2 to 3 times cheaper than epoxies. For all these reasons they are suitable for using as matrix of polymeric composites ${ }^{3}$.

The effect of water absorption on resins used as matrixes for composite applications, including the vinyl ester, has been studied by several authors ${ }^{2,4,5}$. All of them have observed damaging effects and the nature of damage itself, whose degree and intensity depend on the type of resin, temperature, type and amount of initiator, post-cure treatment, among others, what turns the evaluation very complex, since processing and environment plays a crucial role on how resistant the polymeric material will be.

Studies have shown that weight loss during to exposure to water is affected by type and amount of initiator, the post-curing treatment, relative humidity and temperature ${ }^{2,4-6}$. Post-curing treatment reduces weight loss significantly while higher temperatures and relative humidity increases the weight loss rate. Exposure to water also changes glass transition temperature and may lead to extraction of short chain molecules, affecting flexural modulus ${ }^{4,6}$. Other phenomena such as swelling and leaching of non-bounded substances have been also observed $^{5,6}$.

Most published data on cast resins studied ageing mechanisms without correlating degradation to mechanical properties. Few works on water absorption of vinyl ester resins presented the effect of the hygrothermal ageing on the mechanical properties of the neat resin ${ }^{4,6,7}$ 


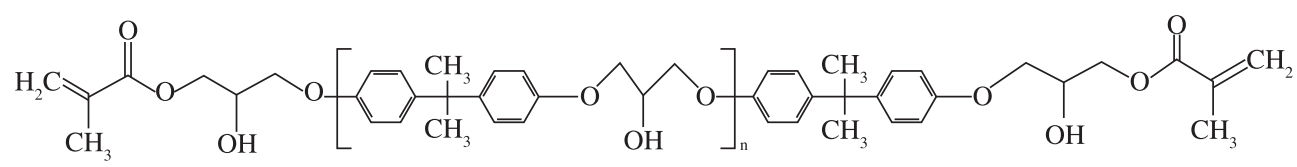

Figure 1. Chemical structure of the epoxy vinyl ester monomer.

and on the fracture surface ${ }^{8}$. Additionally, fracture surface appearance of epoxy systems has been studied ${ }^{9-11}$ and has been correlated to the failure mechanisms ${ }^{10}$, although no similar studies have been found for vinyl-ester systems.

The objective of the present work is to study the effect of the exposition of a vinyl ester system, without post cure treatment, to distilled water at $60^{\circ} \mathrm{C}$ on its mechanical properties (tensile strength, fracture strain, Young modulus and fracture toughness) and fracture mechanisms. Calorimetric and surface morphology analyses were also done to help to understand the mechanical behavior of the resin system prior and after ageing. Additionally, fractographic analysis of the fracture surfaces was carried out in order to understand the failure mechanisms and how they are affected by hygrothermal ageing.

\section{Experimental}

\subsection{Materials}

The material studied was an epoxy vinyl ester resin (Derakane ${ }^{\circledR}$ 411-350, Dow Chemical Co.) containing 45\% styrene. The curing agent was methyl ethyl ketone peroxide (MEKP) supplied as Butanox LPT (Akzo), and the catalyst system used was a solution of 6 wt. (\%) of cobalt octoate in dibutyl phthalate supplied as NL51P (Akzo).

\subsection{Sample preparation}

The polymer was prepared by first mixing the resin and the accelerator $(0.3 \mathrm{wt} .(\%))$, followed by the addition of the initiator (1.5 wt. (\%)). The mixture was stirred for at least 1 minute and cast into silicone rubber moulds. The specimens dimensions followed the ASTMD 638 standard.

In order to verify the effect of hygrothermal aging on the post cure of samples, two cure schedules were carried out. In the samples that would be aged, the cure time was 15 days at room temperature. The other specimens were cured during 24 hours at room temperature followed by a post cure treatment according to the Dow Chemical Co. specification $\left(2\right.$ hours at $120^{\circ} \mathrm{C}$ ).

The specimens were removed from the moulds and their surfaces and edges were ground for minimizing surface defects and for guaranteeing specimens with flat and parallel sides. The nominal dimensions of the specimens used are shown in Figure 2.

\subsection{Hygrothermal ageing and water content determination}

The specimens were subjected to hygrothermal ageing by immersion in distilled water at $60{ }^{\circ} \mathrm{C}$ for different periods of time (16, 36 and 64 days). Weight changes were monitored by repeated weighting of the samples using an Ohaus analytical balance with $0.0001 \mathrm{~g}$ resolution. From the obtained values the percent weight change was calculated. These aged samples were subjected to tensile tests to evaluate the influence of the hygrothermal conditions on the tensile properties. Optical microscopy was used to investigate surface modification after hygrothermal ageing.

The water content was measured in replicates of six. The percent weight change during immersion was calculated using the following equation:

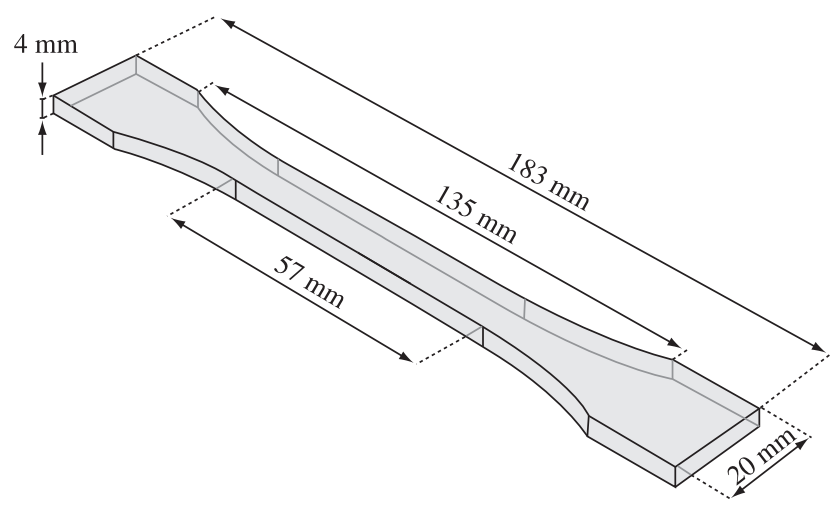

Figure 2. Schematic of the tensile specimens.

$$
w t .(\%)(t)=\frac{w(t)-w(0)}{w(0)} \times 100
$$

where wt. $(\%)$ is the percent weight change at time $t, w(t)$ is the weight of the specimen test at time t, and $w(0)$ is the dry polymer weight.

\subsection{Mechanical analysis}

Tensile tests of the samples were made at room temperature using an Instron mechanical testing machine, model TTDML, with a load cell of $2.5 \mathrm{kN}$, extensometer model G-51-12-A, and loading rate of $0.5 \mathrm{~mm} / \mathrm{min}$. The extensometer was located at the center of specimens with gage length of $25.4 \mathrm{~mm}$.

The tensile strength, elasticity modulus, strain at fracture and fracture toughness values were obtained. Fracture toughness was measured from the area under the curve stress-strain of the tensile tests.

\subsection{Fractography}

The fracture surfaces of mechanically tested specimens were analyzed using a stereo microscope Stemi, model SV6 KL 1500.

\subsection{Differential thermal analysis}

Differential Scanning Calorimeter (DSC) thermograms were obtained using a Perkin-Elmer DSC-7 apparatus. Two scans were made at 40 to $200{ }^{\circ} \mathrm{C}$ with heating rate of $10^{\circ} \mathrm{C} / \mathrm{min}$, followed by a fast cooling (200 to $40{ }^{\circ} \mathrm{C}$ ) and reheating at the same rate. All tests were conducted in nitrogen atmosphere at $10 \mathrm{cc} / \mathrm{min}$.

\section{Results and Discussion}

\subsection{Hygrothermal ageing}

Figure 2 presents the percent weight change of samples as a function of the square root of immersion time. The solid line in the same figure shows the sigmoidal fitting for the experimental data assuming Fickian diffusion. 


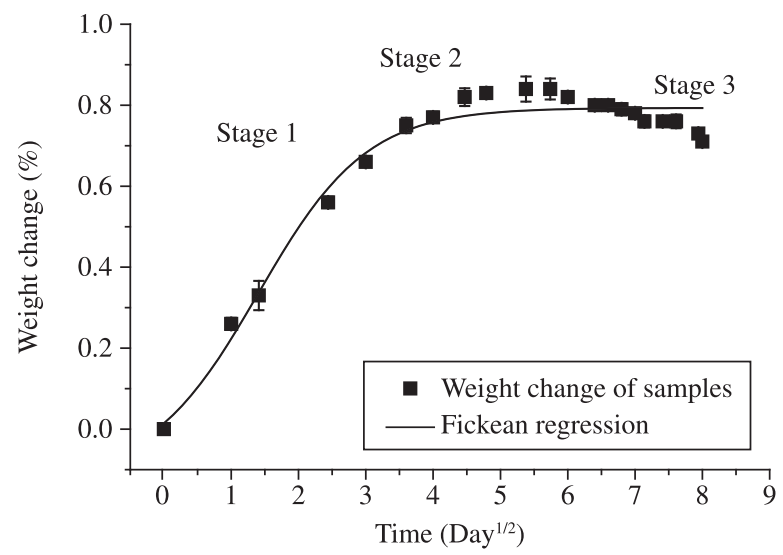

Figure 3. Weight change of resin with water immersion time. Dots correspond to experimental data and solid line was obtained by fitting considering Fickean behavior.

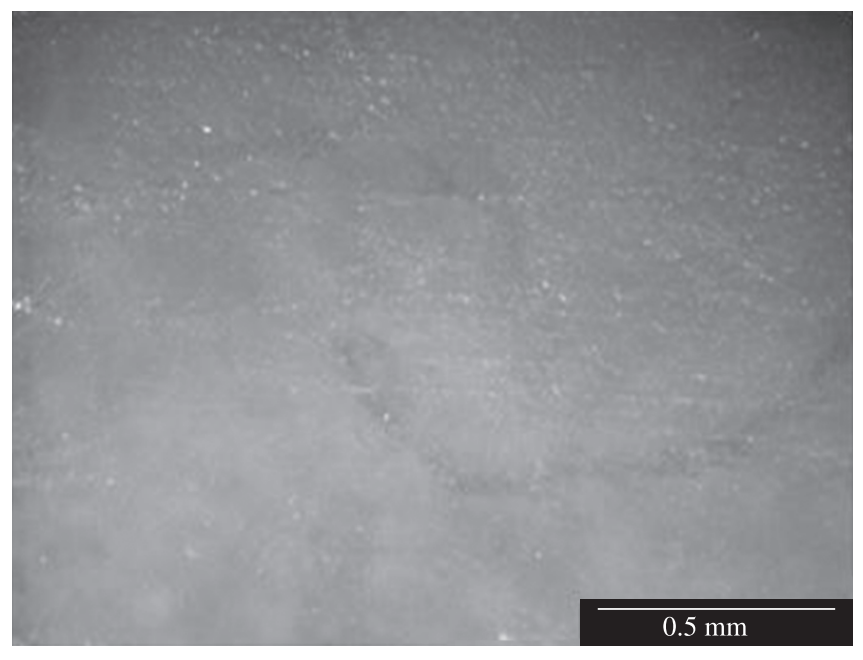

0 Days

(a)

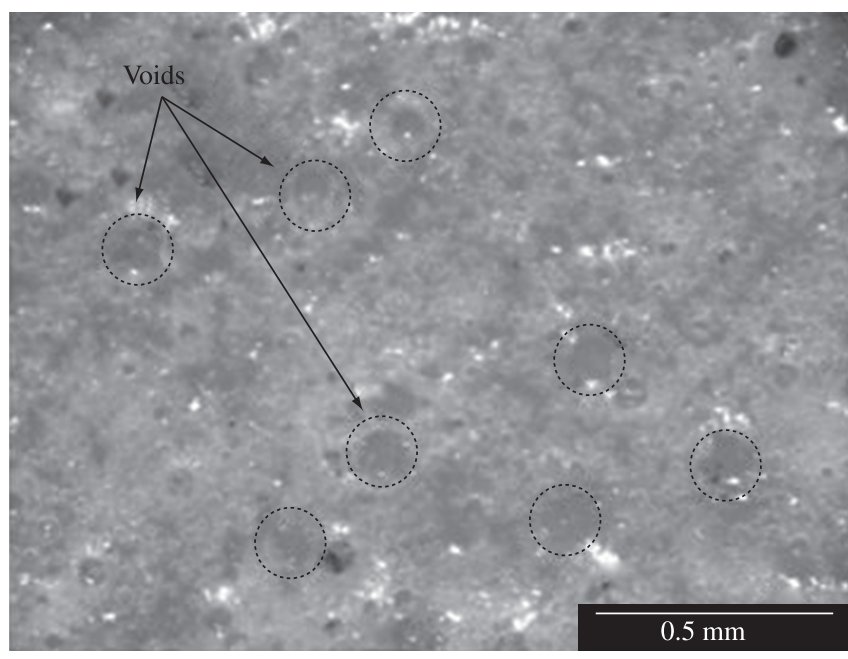

36 Days

(c)

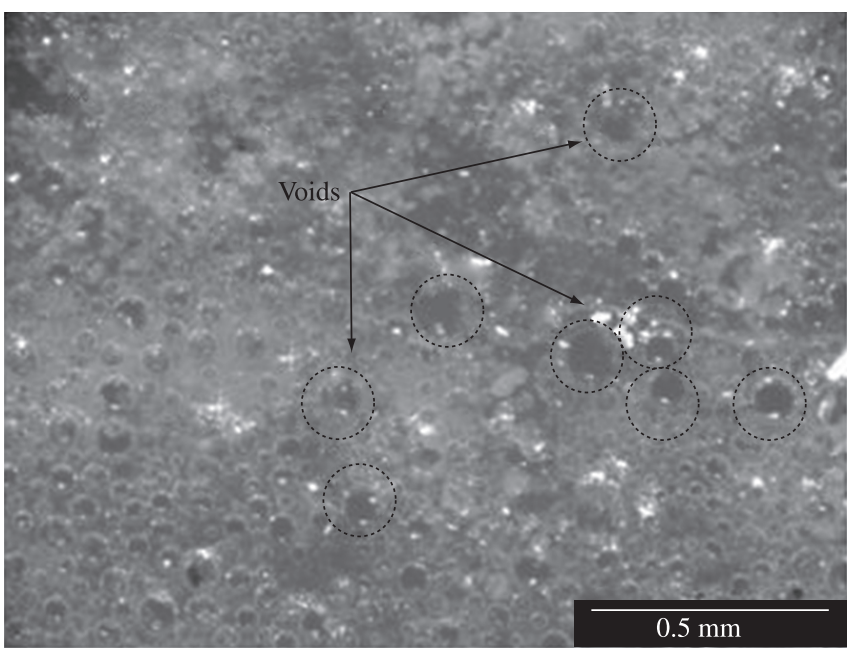

16 Days

(b)

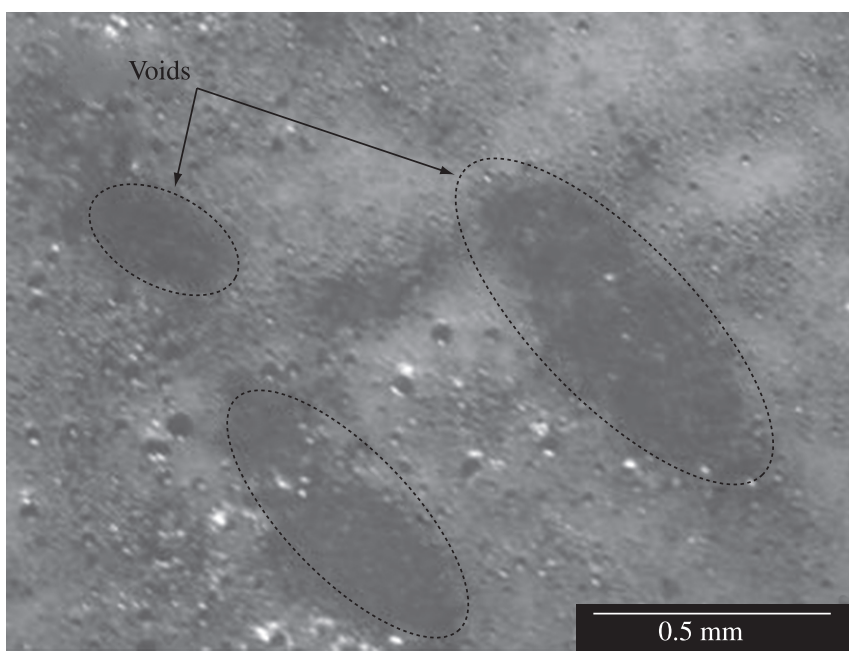

64 Days

(d)

Figure 4. Micrographs of surfaces of the samples: a) before and after b) 16, c) 36 and d) 64 days of hygrothermal ageing. 
The experimental curve shows a Fickian behavior up to approximately 51 days of immersion in water (corresponding to 7.1 days $^{1 / 2}$ in Figure 3), where the fitted and experimental saturation values were close to 0.79 and $0.80 \%$, respectively (stage 1 ). The experimental values showed then a slight deviation from the Fickian fitting curve (stage 2), followed by a drop in weight (stage 3). At this point, the desorption process overcomes sorption.

This behavior indicates the occurrence of 2 kinetically distinct phenomena: water molecules sorption that leads to the increase in sample weight that ends at a short period, followed by a weight decrease, probably associated to desorption of low molecular weight groups. This weight loss phenomenon was also observed for other different polymeric systems and reported by several authors ${ }^{2,4-12}$. In the work of Fraga et al. ${ }^{4}$, weight loss was not observed in the curve of weight change, but the presence of voids detected after immersion and an analysis by FTIR pointed out the extraction of low molecular weight molecules. According to Abeyshinghe et al..$^{5}$ the weight loss mechanism can be accounted to diffusion of residual volatile, chemical scission of the ester groups mainly for polyester resins, or hydrolysis and diffusion of residues induced by cracks and leaching. The observation of cracks and leaching in the present work will be discussed later on.

From the solution of Fick's second law, the diffusion coefficient was calculated using the equation:

$$
\frac{M_{t}}{M_{\infty}}=\frac{4}{\ell}\left(\frac{D t}{\pi}\right)^{1 / 2}
$$

where $\mathrm{M}_{\mathrm{t}}$ is the fluid quantity that has diffused in a time $\mathrm{t} ; M \propto$ is the value of fluid sorved in the beginning of saturation, $l$ is the sample's thickness and D is the diffusion coefficient ${ }^{13,14}$.

A diffusion coefficient value of $7.04 \times 10^{-8} \mathrm{~cm}^{2} / \mathrm{s}$ was obtained considering: $l=6 \mathrm{~mm}$. The values of $\mathrm{M} \infty(0.80 \%$ for $\mathrm{t}=44$ days $)$ and $\mathrm{M}_{\mathrm{t}}(0.332 \%$ for $\mathrm{t}=2$ days $)$ were obtained from the water absorption curve at $60{ }^{\circ} \mathrm{C}$.

It is known that the diffusion coefficient can be calculated from the solution of Fick's second law of diffusion ${ }^{2,4}$. Fick's law is applied only when there is no chemical interaction between the absorbed water and materials, for materials without weight loss. Nonetheless, this procedure has been employed despite the observance of chemical interactions, assuming that at initial stages of immersion such reactions are not significant. The results are quite dispersive though. Although the weight variation curve has a Fickian profile, there is no way of determining exactly when chemical interaction takes place. Both phenomena, absorption of water and leaching of degraded material, may occur simultaneously. The gain of weight means that absorption is the dominant process.

Lee et al. ${ }^{2}$ reported also that the difficulty encountered in obtaining data from samples exposed to $100 \%$ r.h. resulted from the tendency of water to cluster in some resins and from cracking in other resins. According to the authors, some polyester and vinyl ester resins show a weight loss after reaching a maximum, especially at $65^{\circ} \mathrm{C}$, and the values $\mathrm{M} \infty$ taken as the maximum in the weight gain curves in some cases are not the true ones. Lee et al. ${ }^{2}$ described that the true diffusion parameter $\mathrm{D}$ cannot be obtained for a polymer which shows a significant weight loss, since this value depends upon $\mathrm{M} \infty$.

In previous studies with vinyl ester resin Fraga et al. ${ }^{4}$ estimated the diffusion coefficient at 40 and $80{ }^{\circ} \mathrm{C}$ in $2.19 \times 10^{-8} \mathrm{~cm}^{2} / \mathrm{s}$ and $1.56 \times 10^{-7} \mathrm{~cm}^{2} / \mathrm{s}$, respectively. Lee et al..$^{2}$ estimated a diffusion coefficient of $22.5 \times 10^{-8} \mathrm{~cm}^{2} / \mathrm{s}$ at $65^{\circ} \mathrm{C}$ and $75 \%$ r.h. Ellis and Found ${ }^{15}$ obtained for a polyester resin, cured with MEKP catalyst and cobalt accelerator, a diffusion coefficient of of $3.8 \times 10^{-8} \mathrm{~cm}^{2} / \mathrm{s}$ at $44.4{ }^{\circ} \mathrm{C}$. Harper and $\mathrm{Naeem}^{16}$ found values for glass fiber reinforced vinyl ester composites of $1.145 \times 10^{-9} \mathrm{~cm}^{2} / \mathrm{s}$ at $60^{\circ} \mathrm{C}, 6.76 \times 10^{-9} \mathrm{~cm}^{2} / \mathrm{s}$ at $25^{\circ} \mathrm{C}$, $9.605 \times 10^{-9} \mathrm{~cm}^{2} / \mathrm{s}$ at $50{ }^{\circ} \mathrm{C}$ and $1.288 \times 10^{-8} \mathrm{~cm}^{2} / \mathrm{s}$ at $70{ }^{\circ} \mathrm{C}$.

After 16 days of immersion, a "viscous white" layer was visible on the sample surfaces as well as small voids. When the immersion time was increased, the white layer become thicker and an increase in the number and size of voids could be clearly observed. Figure 4 shows the resin surfaces after $0,16,36$ and 64 days of hygrothermal ageing. Some voids are indicated by arrows in the figure. As can be observed, previously to the hygrothermal ageing the surface was clear and smooth.

The work of Abeysinghe et al. ${ }^{5}$, Fraga et al. ${ }^{4}$ and Apicella et al. ${ }^{6}$ also reported similar changes in the aspect of several types of resins after water absorption. They observed the development of voids on the surface and inside the polymer with simultaneous loosing of resin in the process. Apicella et al. ${ }^{6}$ observed in isophthalic polyester resins the appearance of a large number of cracks randomly distributed in the bulk resin after 5 days of immersion in distilled water at $90{ }^{\circ} \mathrm{C}$. The same phenomenon, although less evident, was also observed in bisphenol-B resin after 15 days of exposition, under same conditions of isophthalic resin. Abeysinghe et al. ${ }^{5}$ observed in isophthalic resin, after immersion in distilled water at $65^{\circ} \mathrm{C}$, the appearance of "disc cracks" and a white substance. The authors reported that sometimes the cracks were formed first within the bulk of the sample and in other cases they were observed first on the surfaces.

\subsection{Mechanical tests}

In order to understand how the mechanical properties are affected by the occurrence of weight loss and surface voids, tensile mechanical tests were carried out prior and after hygrothermal ageing. Figure 5 shows the stress-strain curve for the resin before and after ageing for 16, 36 and 64 days.

Before ageing, a ductile behavior with elongation at failure close to $8 \%$ was observed. After 16 days of ageing this behavior was severely modified and a typical brittle behavior was observed, with large increase in mean fracture stress, an abrupt increase in elasticity modulus, as well as a significant drop in the mean strain at fracture and toughness values. It is likely that post cure of the system took place after the immersion of the sample in water at $60{ }^{\circ} \mathrm{C}$. Although in the present work the curing time of the resin was 15 days at
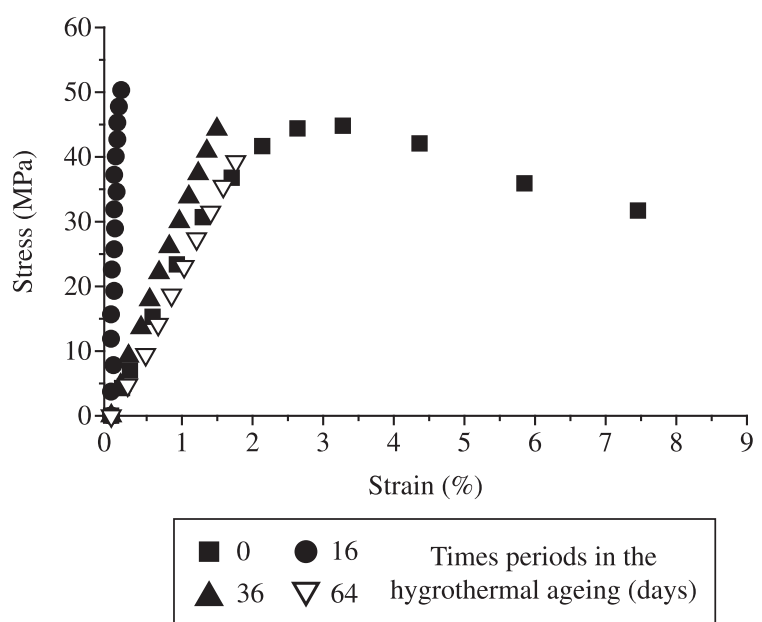

Figure 5. Typical stress-strain curves of the samples before and after hygrothermal ageing. 


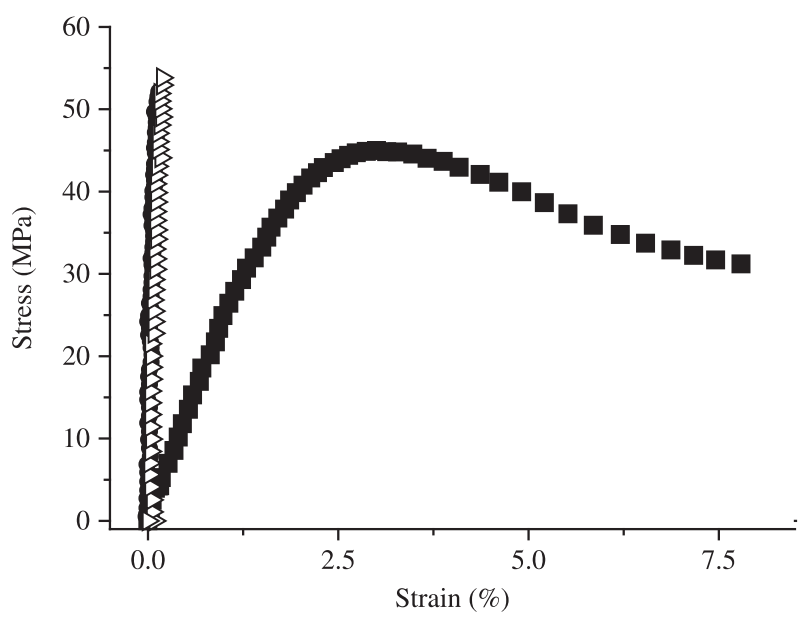

Without ageing

After 16 days of ageing

$\triangleright$ Post cured $\left(2\right.$ hours at $\left.120{ }^{\circ} \mathrm{C}\right)$

Figure 6. Typical stress-strain curves of the samples before, after 16 days of hygrothermal ageing and with post cure treatment.

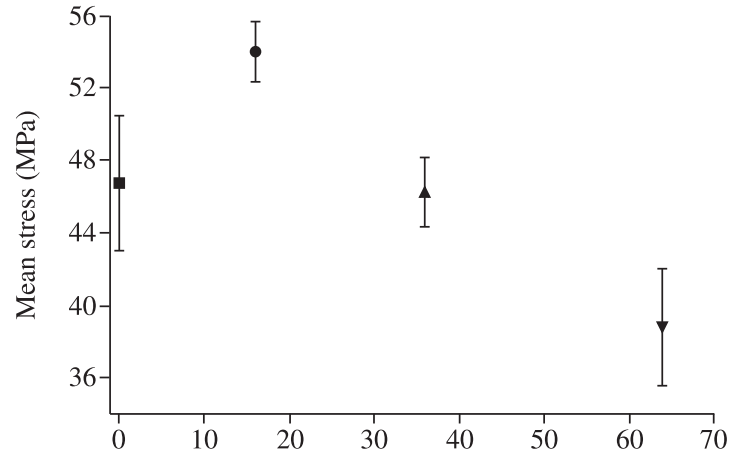

(a)

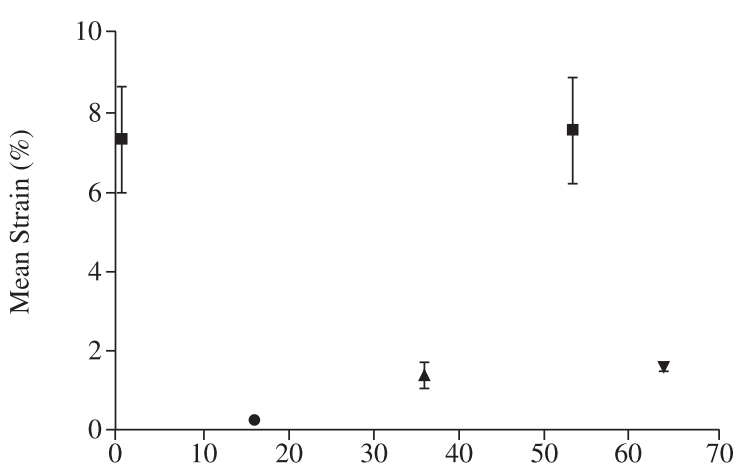

(c)

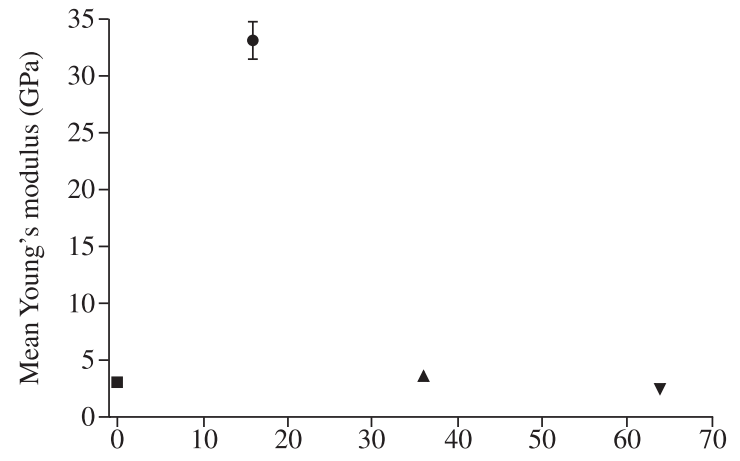

(b)

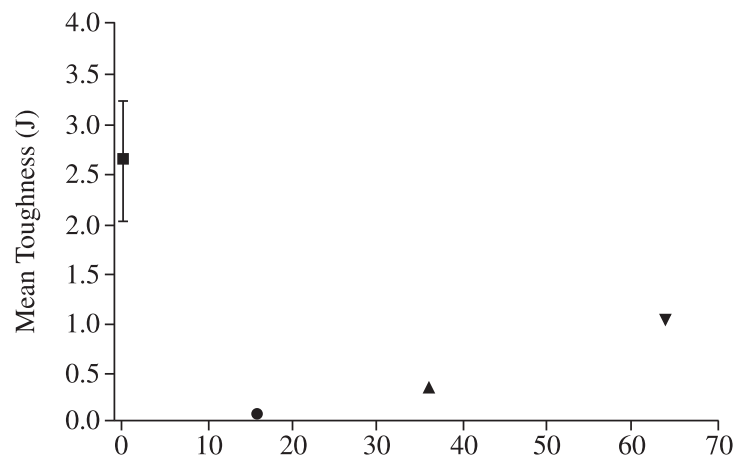

(d)

$$
\begin{array}{lll}
\text { - } 0 & \bullet 16 \\
\text { - } 36 & \text { v } 64
\end{array}
$$

Time perriods of hygrothermal ageing (days)

Figure 7. Mechanical properties of samples as function of hygrothermal ageing time. a) mean fracture stress, b) mean Young modulus, c) mean fracture strain and d) mean toughness. 
room temperature, the low mobility of chains due to the very high viscosity could prevent complete curing reaction. When samples were immersed in water at elevated temperatures, the system probably regained mobility and the unreacted monomers were allowed to finish the curing process due to the relatively high temperature of water. The result was a drastic change observed in the mechanical characteristics. According to the literature ${ }^{6,12}$ this embrittlement of resins dissolved in a polymerizable monomer such as styrene, which is the case of the vinyl ester considered herein, may be due to a post-cure effect caused by residual styrene monomers reaction and/or loss of low molecular weight segments present in the polymeric system.

The results of tensile test and thermal analysis of the samples submitted to the post cure treatment $\left(2\right.$ hours at $120^{\circ} \mathrm{C}$ ) confirmed the occurrence of post cure in the samples aged in water during 16 days at $60{ }^{\circ} \mathrm{C}$. The mechanical and thermal behavior of both sample sets was rather similar. Figure 6 shows the stress-strain curves for these samples. It can be observed that the post cure of all samples, regardless of the way they were conducted (16 days of ageing or post cure treatment), promoted the same changes on the mechanical properties: increase in the tensile strength, a large drop in the strain at fracture and an abrupt increase of the elasticity modulus.

After 36 days of ageing the brittle characteristics remained, although the existence of a slight increase in strain and toughness values and a decrease of elasticity modulus. After 64 days of ageing, both strain and toughness values increased with relation to the samples treated for periods of 16 and 36 days. This behavior is shown by the graphs of Figure 7 where the mechanical properties are plotted against hygrothermal ageing times.

Initially, it was observed an increase in the tensile strength value, which changed from 47.67 to $53.93 \mathrm{MPa}$ after 16 days of immersion. Subsequently, a linear decrease of this mechanical property took place, changing from 53.93 to $46.18 \mathrm{MPa}$ and $38.74 \mathrm{MPa}$ after 36 and 64 immersion days, respectively. The mean strain at fracture value presented an abrupt drop after 16 immersion days, changing from $8.03 \%$ (unaged - 0 immersion days) to $0.19 \%$, indicating the embrittlement of the resin system. After 36 and 64 days the ductility presented a gradual increase, changing to 1.38 and to $1.65 \%$, respectively. However, the resin system remained brittle. The elasticity modulus value also increased abruptly after 16 days of immersion, changing from 2.42 to $32.59 \mathrm{GPa}$. Subsequently, it had a sharp drop to $2.81 \mathrm{GPa}$, after 36 days, and to $2.37 \mathrm{GPa}$ after 64 days. As the strain, the fracture toughness value presented, initially, an abrupt drop after 16 days of immersion, changing from 2.37 to $0.035 \mathrm{~J}$. After that, it presented a gradual increase, changing to 0.34 and to $1.07 \mathrm{~J}$, after 36 and 64 days, respectively.

\subsection{Differential thermal analysis}

In order to verify the occurrence of post-cure reaction during hygrothermal ageing, thermal analyses were carried out for all samples.

Two heating scans were performed in all samples. The purpose of the first scan was to allow the observation of any type of thermal process during heating in the DSC. In the second scan, it was possible to obtain the glass transition temperature $\left(\mathrm{T}_{\mathrm{g}}\right)$. The $\mathrm{T}_{\mathrm{g}}$ is an important parameter since it establishes the service temperature. Usually, when the material is exposed to a hygrothermal environment the $\mathrm{T}_{\mathrm{g}}$ decreases and, therefore, the service temperature of the material changes. Additionally, a post-cure reaction is associated to an increase in $\mathrm{T}_{\mathrm{g}}$.

Figure 8 shows the DSC thermograms for all samples. In the unaged samples the first scan presents a characteristic feature of exothermic reaction, indicating a possible cross-link due to incomplete cure of the system.
Exothermic peaks are related to the cure process, i.e., the energy involved in the cross-linking reaction of resin reactive groups ${ }^{17}$. According to the literature ${ }^{18,19}$, a post cure treatment is necessary for producing stable polymeric systems and for avoiding any residual exothermic reactions.

This thermal behavior corroborates the findings on the mechanical analysis, showing that indeed without an adequate cure treatment the polymer is chemically unstable due to the presence of residual reactive sites, which reflects in the ductile behavior observed in Figure 5. In the second scan, after a complete cure of the polymeric system in DSC, it was possible to obtain the $\mathrm{T}_{\mathrm{g}}$ of the sample, which was $117.20^{\circ} \mathrm{C}$.

After 16 days of ageing, it was observed the complete cure of the system, reached due to the favorable condition of chain mobility (ageing at $60^{\circ} \mathrm{C}$ ). In this case, the $\mathrm{T}_{\mathrm{g}}$ was $118.54^{\circ} \mathrm{C}$. The same behavior was observed in the sample submitted to the post cure treatment, i.e., absence of exothermal peak and similar $\mathrm{T}_{\mathrm{g}}$ values $\left(117.97{ }^{\circ} \mathrm{C}\right)$. The cross-links lead to a more rigid system, where the chains are tightly connected. Mechanically, this reflects in the brittle behavior observed in both sample sets. After 36 and 64 days of hygrothermal ageing both thermograms indicate the presence of endothermic reactions that could be related to resin plasticization by water sorption and crosslink breaking. At this point, the water had penetrated into the resin and a plasticizer effect is observed. This process was associated to a gradual drop in $\mathrm{T}_{\mathrm{g}}$ values, which changed from $118.54{ }^{\circ} \mathrm{C}$ (in the sample with complete cure after 16 days) to 110.77 and to $107.65^{\circ} \mathrm{C}$ after 36 and 64 immersion days, respectively. The physical interaction of moisture with vinyl ester resin promotes a subsequent reduction of $\mathrm{T}_{\mathrm{g}}$, through resin plasticizing ${ }^{20}$. This modification in $\mathrm{T}_{\mathrm{g}}$ reflects in the mechanical properties as can be observed in Figures 5 and 7, where after 16 days a drop in the Young modulus and an increase in ductility were observed, as discussed previously.

It must be emphasized that the effect of hygrothermal ageing and post-cure are expected to be simultaneous and competitive. This is indeed shown in micrographs in Figure 4, where even after 16 days voids and growth of the white layer that indicates degradation of the resin occurred, though the post-cure process was also taking place.

\subsection{Fractography}

The fracture surface of thermoset polymers is characterized by the presence of three different regions: A) a flat featureless mirror region surrounding the crack initiation point; B) a transition region, where the surface roughness steadily increases and C) a final propagation region with conical marks ${ }^{21}$. According to Lin and $\mathrm{Chen}^{22}$ this conic shaped pattern is due to the intersection between a moving planar crack front and a radically growing circular craze or secondary crack front. The fracture surface patterns are dependent on the ratio of crack velocity to craze or secondary crack velocity and changes from flat parabolas to ellipses, and finally to an approximate circle when the ratio of crack velocity to craze or secondary crack velocity continually increases.

The overall aspects of the fracture surface morphology of a thermoset polymer are shown in Figure 9a. Of particular relevance for this study is the size of the mirror region, which has been correlated with the toughness of polymers and particulate composites ${ }^{23,24}$. The smaller the mirror region, the more brittle the material is. As shown in Figure 9, the mirror zone of the sample with 16 days of ageing (which had post cure confirmed) and with post cure treatment is smaller than the unaged sample or the samples in which plasticization effect was verified.

In the unaged samples, it can be observed the presence of a large crack initiation region that indicates, according to theoretical thermoset polymer crack propagation, that a significant energy 


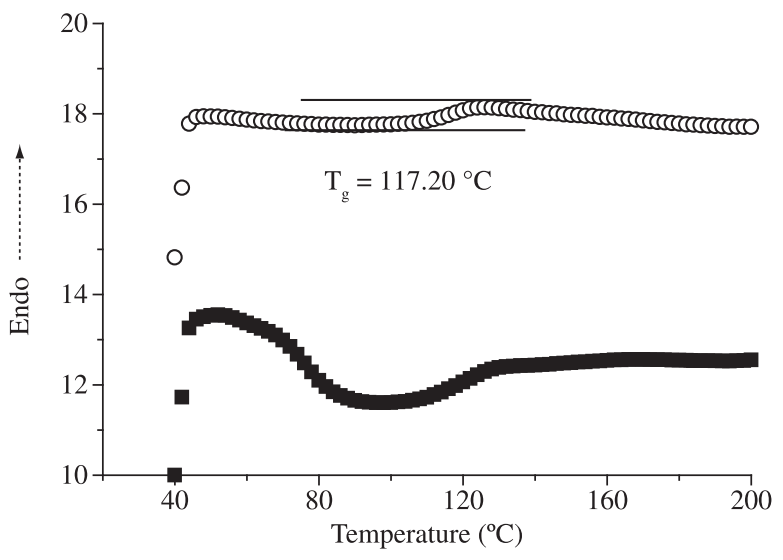

(a)

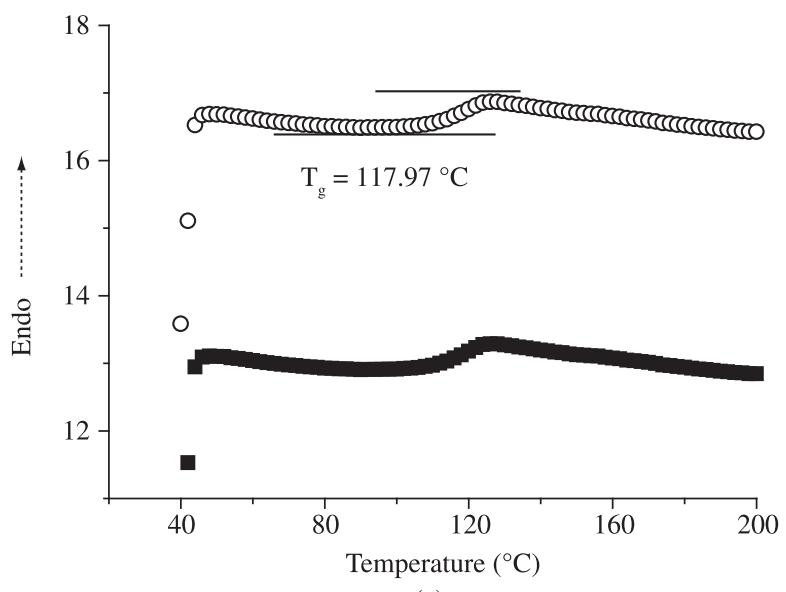

(c)

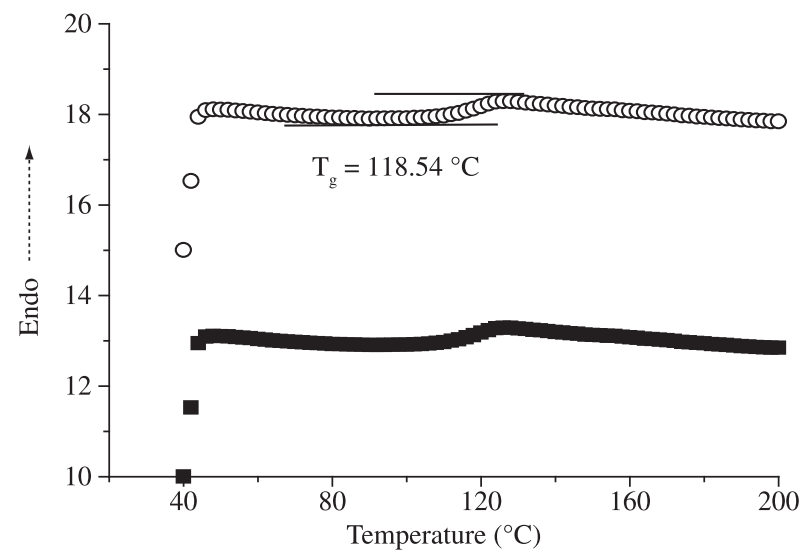

(b)

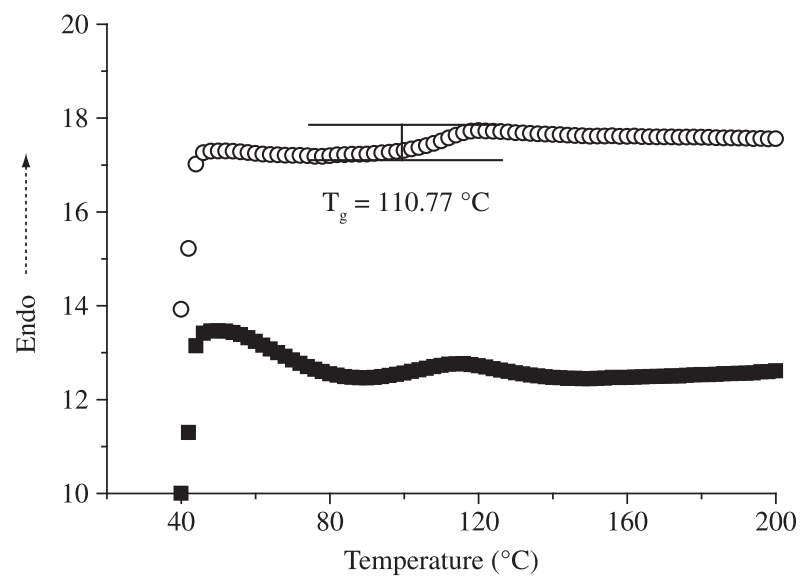

(d)

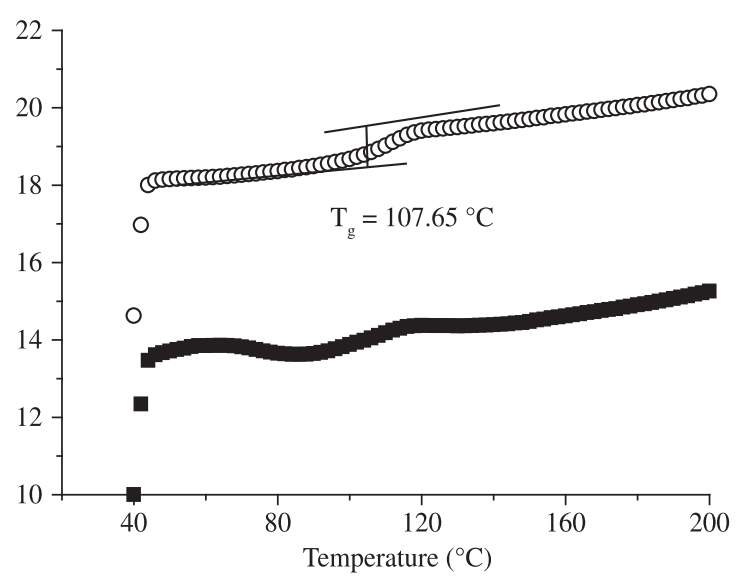

(e)

Scan $1 \bigcirc$ Scan 2

Figure 8. DSC thermograms of specimens: a) unaged, b) after 16 days of ageing, c) with post cure treatment, d) and e) after 36 and 64 days of ageing, respectively.

value was necessary for crack initiation ${ }^{23}$. This ductile behavior is also shown in the stress-strain curve which presented elongation at failure close to $8 \%$, related to the absence of post cure treatment in the polymeric system. The high value in elongation at failure observed in this sample can be related to smaller cross-linking density (spacing between successive cross-link sites). The properties of a cured epoxy resin depend principally on the cross-link density.
In general, the tensile modulus, glass transition temperature, and thermal stability as well as chemical resistance are improved with increasing cross-link density, but strain-to-failure and fracture toughness are reduced. Factors that control the cross-link density are the chemical structure of the starting liquid resin, functionality of curing agent, and the reaction conditions, such as temperature and time. 


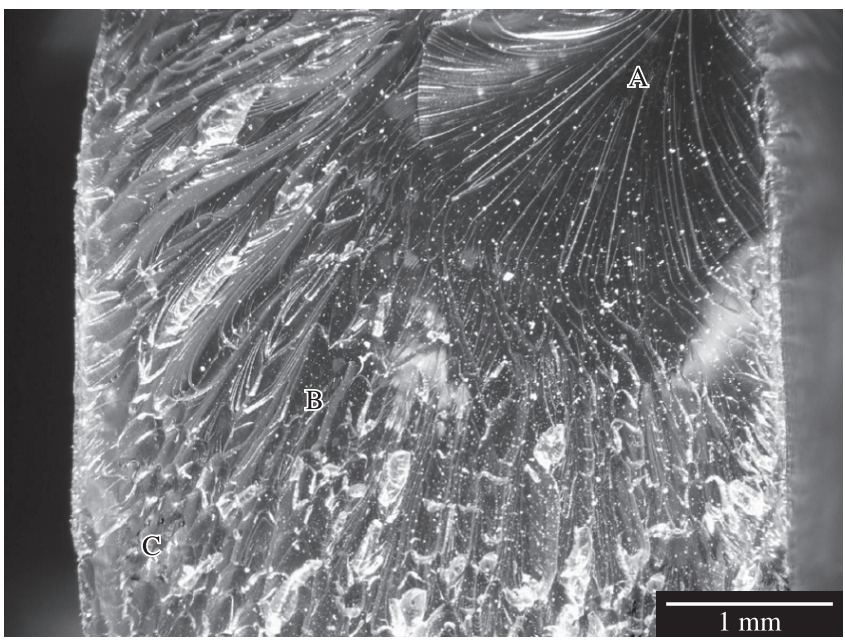

(a)

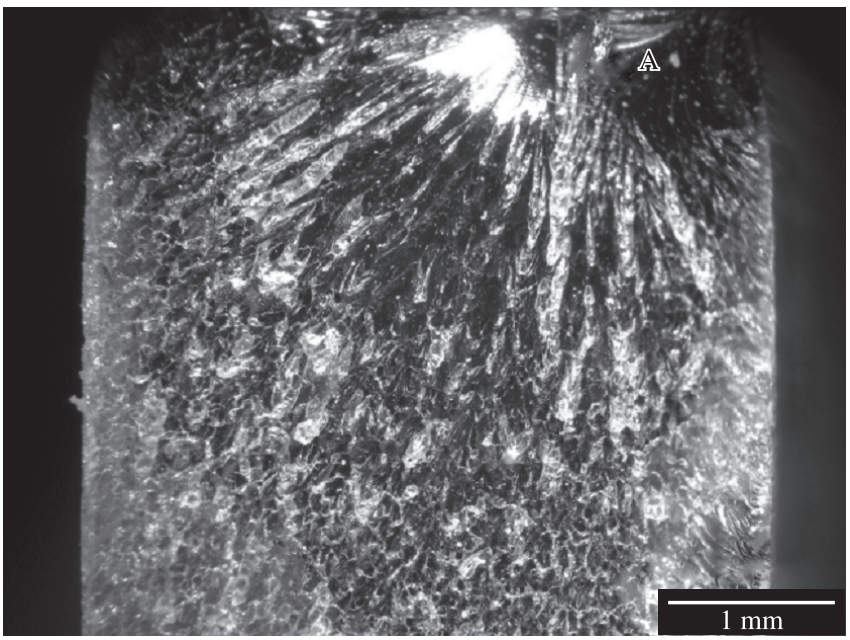

(c)

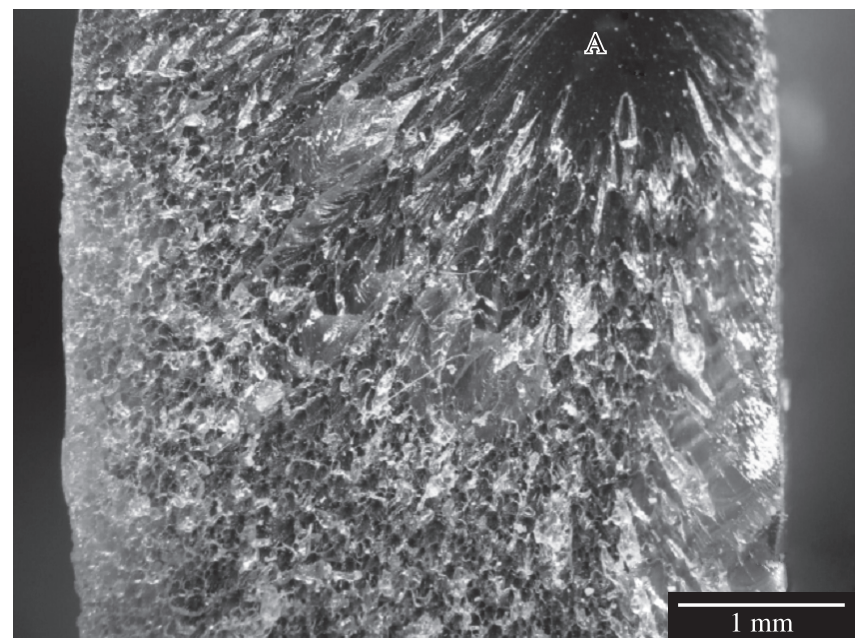

(b)

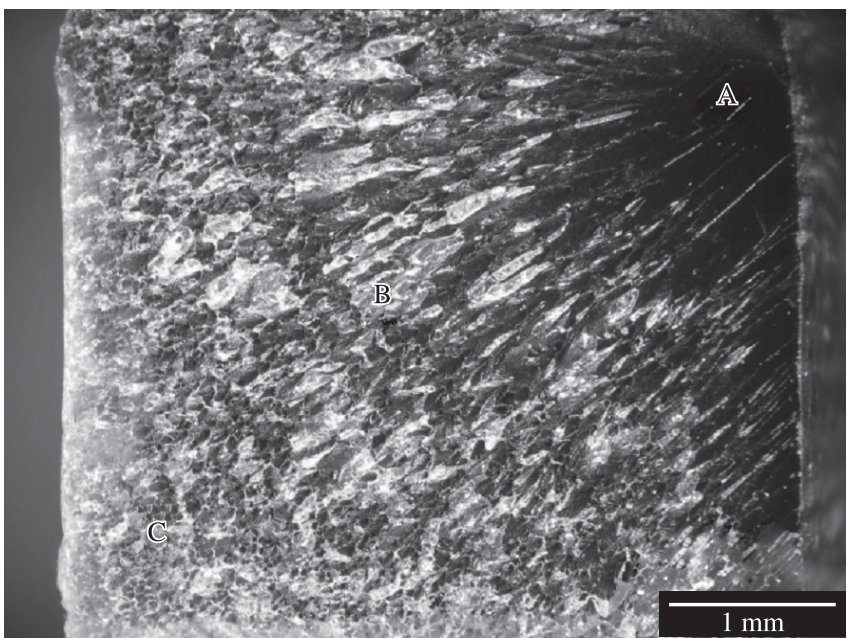

(d)

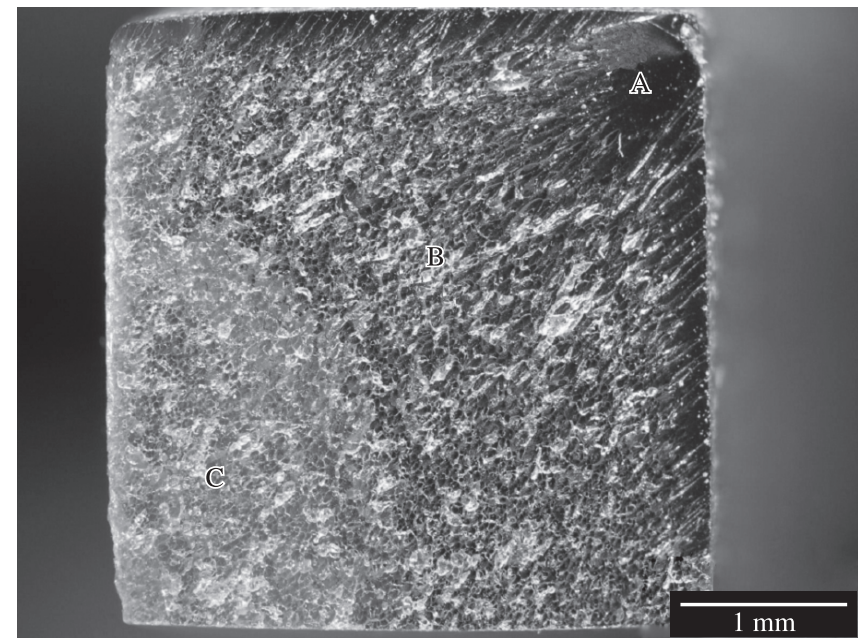

(e)

Figure 9. Fracture surface morphology of the samples a) without ageing, b) after 16 days of hygrothermal ageing, c) with post cure treatment, d) and e) after 36 and 64 days of hygrothermal ageing, respectively. 
The brittle behavior observed in the stress-strain curves of the samples with 16 days of hygrothermal ageing and with post cure treatment are characterized by the shattering on fracture surface. Therefore, it was not possible to distinguish the $\mathrm{B}$ and $\mathrm{C}$ fracture regions. In both cases, this brittle behavior is related to the effect of the post cure which promoted the increase of cross-link density and, consequently, resulted in a more rigid system.

\section{Conclusions}

Initially, the absence of a post-cure treatment in the vinyl ester resin system studied herein generated an unstable system. The unaged samples presented ductile behavior with elongation at fracture close to $8 \%$. This ductile behavior was severely modified to brittle after 16 days of hygrothermal ageing at $60{ }^{\circ} \mathrm{C}$ due to the increase of crosslink showed by calorimetric analysis. This increase leads to a more rigid system. Mechanically, this reflects in this brittle behavior. The mean strain at fracture value changed from $8.03 \%$ (unaged sample) to $0.19 \%$ (after 16 days of ageing).

As expected, the samples aged during 16 days in water at $60{ }^{\circ} \mathrm{C}$ presented the same properties as the ones submitted to the post cure treatment.

Later on, water acted as plasticizer, decreasing the $\mathrm{T}_{\mathrm{g}}$ and the elasticity moduli of samples after 36 and 64 days of ageing. The mean elasticity modulus value had a remarkable drop from $32.59 \mathrm{GPa}$ (after 16 days of ageing) to $2.81 \mathrm{GPa}$ (after 36 days) and to $2.37 \mathrm{GPa}$ (after 64 days). As the strain, the mean fracture toughness value presented, initially, an abrupt drop after 16 days of immersion, changing from 2.37 to $0.035 \mathrm{~J}$ and subsequently, it gradually increased to 0.34 and to $1.07 \mathrm{~J}$, after 36 and 64 days, respectively.

This transition from ductile to brittle has been also characterized by fracture surfaces of the samples.

\section{Acknowledgements}

The authors acknowledge the financial support of CAPES, CNPq and CNPq/CT-PETRO. The authors are also grateful to Prof. Verônica Calado and IMA/UFRJ for making available laboratorial facilities.

\section{References}

1. Merdas I, Thominette F, Tharkhtchin A and Verdu J. Factors governing water absorption by composite matrices. Composites Science and Technology 2002; 62: 487-492.

2. Lee SB, Rockett TJ and Hoffman RD. Interactions of water with unsaturated polyester, vinyl ester and acrylic resins. Polymer 1992; 33(17): 3691-3697.

3. Abadie MJM, Mekhissi K and Burchill PJ. Effects of processing conditions on the cure of a vinyl ester resin. Journal of Applied Polymer Science 2001; 84: 1146-1154.

4. Fraga AN, Alvarez VA and Vázquez A. Relationship between dynamic mechanical properties and water absorption of unsaturated polyester and vinyl ester glass fiber composites. Journal of Composite Materials 2003; 37(17): 1553-1573.

5. Abeysinghe HP, Edwards W, Pritchard G and Swampillai GJ. Degradation of crosslinked resins in water and electrolyte solutions. Polymer 1982; 23: $1785-1790$
6. Apicella A, Migliaresi C, Nicolais L, Iaccarino L and Roccotelli S. The water ageing of unsaturated polyester-based composites: influence of resin chemical structure. Composites 1983; 14(4): 387-392.

7. OdeLa Osa, Alvarez VA, Fraga AN, Mammone M and Vázquez A. Loss of Mechanical Properties by Water Absorption of Vinyl-ester Reinforced with Glass Fiber. Journal of Reinforced Palstics and Composites 2006; 25(2): 215-221.

8. Auad ML, Frontini PM, Borrajo J and Araguren MI. Liquid rubber modified vinyl ester resins: fracture and mechanical behavior. Polymer 2001; 42: 3723-3730.

9. Yamini S and Young RJ. Stability of crack propagation in epoxy resins. Polymer 1977; 18: 1075-1080.

10. Lin YC and Chen Xu. Investigation of the effect of hygrothermal conditions on epoxy system by fractography and computer simulation. Materials Letters 2005; 59: 3831-3836.

11. d'Almeida JRM, Menezes GW and Monteiro SN. Ageing of the DGEBA/ TETA Epoxy System with off-Stoichiometric Compositions. Materials Research 2003; 6 (3): 415-420.

12. Apicella A, Migliaresi C, Nicodemo L, Nicolais L, Iaccarino L and Roccotelli S. Water sorption and mechanical properties of a glass-reinforced polyester resin. Composites 1982; 82: 406-410.

13. Marshall JM, Hope PS and Ward IM. Sorption and Diffusion in Highly Oriented Polyethylene. Polymer 1982; 23: 142-143.

14. Pérez C, Collazo A, Izquierdo M, Merino P and Nóvoa XR. Characterization of the barrier properties of different paint systems Part II. Nom-ideal diffusion and water uptake kinetics. Progress in Organic Coatings 1999; 37: 169-177.

15. Ellis B and Found MS. The effects of water absorption on a polyester/ chopped strand mat laminate. Composites 1983; 14(3): 237-243.

16. Harper JF and Naeem M. The Moisture Absorption of Glass Fibre Reinforced Vinylester and Polyester Composites. Materials \& Design 1989; 10(6): 297-300.

17. Salmoria GV, Ahrens CH, Fredel M, Soldi V and Pires ATN Stereolithography somos 7110 resin: mechanical behavior and fractography of parts post-cured by different methods. Polymer Testing 2005; 24: 157-162.

18. Gautier L, Mortaigne B and Bellenger V. Interface damage study of hydrothermally aged glass-fibre-reinforced polyester composites. Composites Science and Technology 1999; 59: 2329-2337.

19. Tucker R, Compston P and Jar PYB. The effect of post-cure duration on the mode I interlaminar fracture toughness of glass-fibre reinforced vinylester. Composites: Part A 2001; 32: 129-134.

20. Haque A and Hossain MK. Effects of Moisture and Temperature on High Strain Rate Behavior of S2-Glass-Vinyl Ester woven Composites. Journal of Composite Material 2003; 37(7): 627-647.

21. Wolock I and Newman SB. Fracture Processes in polymeric Solids - Phenomena and Theory. In: B. Rosen (editors). New York: ed. Interscience; 1964 . p. 235-290.

22. Lin YC and Chen Xu. Investigation of the Effect of Hygrothermal Conditions on Epoxy system by fractography and Computer Simulation. Materials Letters 2005; 59:3831-3836.

23. Kinloch AJ and Willians JG. Crack Blunting Mechanisms in Polymer. Journal of Material Science 1980; 15: 987-996.

24. Cantwell WJ, Roulin-Moloney AC and Kaiser TJ. Fractography on Unfilled an Particulate-filled epoxy resin. Journal of Material Science 1988; 23:1615-1631. 